\title{
COMPARATIVE EFFICACIES OF SODIUM PERCARBONATE, PERACETIC ACID, AND FORMALDEHYDE FOR CONTROL OF ICHTHYOBODO NECATOR-AN ECTOPARASITIC FLAGELLATE FROM RAINBOW TROUT
}

\author{
Rzgar M. JAAFAR, Jesper A. KUHN, Jiwan K. CHETTRI, and Kurt BUCHMANN* \\ Department of Veterinary Disease Biology, Faculty of Health and Medical Sciences, University of Copenhagen, \\ Frederiksberg C, Denmark
}

Jaafar R.M., Kuhn J.A., Chettri J.K., Buchmann K. 2013. Comparative efficacies of sodium percarbonate, peracetic acid, and formaldehyde for control of Ichthyobodo necator - an ectoparasitic flagellate from rainbow trout. Acta Ichthyol. Piscat. 43 (2): 139-143.

Background. Ichthyobodosis ("costiosis") is induced by the flagellate Ichthyobodo necator in both wild and cultured host populations. Fish farmers for decades have been using formaldehyde (FA) for control but this compound is problematic due to its carcinogenic and allergenic nature. Alternative auxiliary substances for bath treatment are needed and therefore we decided to compare efficacies of sodium percarbonate (SPC), peracetic acid (PAA), and hydrogen peroxide (HP) for control of ichthyobodosis in rainbow trout, Oncorhynchus mykiss.

Materials and methods. An experimental infection of Ichthyobodo necator on rainbow trout (2-3 g) was established (total parasite population up to 142000 flagellates per fish) and duplicated controlled water bath treatments were conducted with specified water quality criteria. Four compounds: SPC $\left(40,80\right.$, and $\left.120 \mathrm{mg} \cdot \mathrm{L}^{-1}\right), \operatorname{PAA}(0.1$, 0.2 , and $\left.0.3 \mathrm{mg} \cdot \mathrm{L}^{-1}\right)$, HP ( 15 and $\left.30 \mathrm{mg} \cdot \mathrm{L}^{-1}\right)$, and FA $\left(40\right.$ and $\left.80 \mathrm{mg} \cdot \mathrm{L}^{-1}\right)$ were tested. The compounds were applied for $2 \mathrm{~h}$ (as static freshwater bath treatments at $13^{\circ} \mathrm{C}$ ) in $20-\mathrm{L}$ aerated tanks (containing $10 \mathrm{~L}$ of the treatment solution).

Results. FA at a concentration of $80 \mathrm{mg} \cdot \mathrm{L}^{-1}$ and PAA at $0.3 \mathrm{mg} \cdot \mathrm{L}^{-1}$ showed almost complete elimination of parasites but it was found that also SPC at a concentration of the $120 \mathrm{mg} \cdot \mathrm{L}^{-1}$ was highly effective in eliminating I. necator. In addition, SPC and PAA $\left(80 \mathrm{mg} \cdot \mathrm{L}^{-1}\right.$ and $0.2 \mathrm{mg} \cdot \mathrm{L}^{-1}$, respectively) also significantly reduced the parasite load compared to untreated control fish. HP significantly reduced parasite populations at a concentration of $30 \mathrm{mg} \cdot \mathrm{L}^{-1}$, but the compound elicited adverse reactions in fish.

Conclusion. It is suggested that SPC and PAA may serve as alternatives to formaldehyde for control of ichthyobodosis in rainbow trout farms.

Keywords: Ichthyobodo necator, rainbow trout, Oncorhynchus mykiss, bath treatment Short running title: Control of ichthyobodosis in rainbow trout

\section{INTRODUCTION}

The ectoparasitic flagellate Ichthyobodo necator is known to induce ichthyobodosis in both wild- and cultured host populations and notably young fish are vulnerable. The parasite infects gills, skin, and fins and causes severe epizootics in aquaria, hatcheries, and rearing ponds worldwide (Urawa and Kusakari 1990, Urawa 1992, Urawa 1993). Rainbow trout (Oncorhynchus mykiss) farming in Denmark is currently suffering from I. necator infections and trout farmers apply formaldehyde bath treatments for control. A series of antiparasitic compounds were tested by Tojo et al. (1994) and Tojo and Santamarina (1998) elucidating efficacies of 11 drugs used for bath treatment and further 32 drugs administered orally against $I$. necator infection of rainbow trout. It was shown that oral treat- ments using metronidazole ( $40 \mathrm{~g} \cdot \mathrm{kg}^{-1}$ feed, 10 days), secnidazole $\left(20 \mathrm{~g} \cdot \mathrm{kg}^{-1}\right.$ feed, 2 days $)$, and triclabendazole (40 g $\cdot \mathrm{kg}^{-1}$ feed, 5 days) were effective and did show elimination of the flagellates. The first two nitroimidazoles are banned for use in fish production within the EU. In addition, although oral medical treatments may have a potential role in future control it is worth investigating auxiliary water bath treatments based on environmentallyfriendly compounds. Recently Farmer et al. (2013) tested copper sulphate, potassium permanganate, and peracetic acid against $I$. necator infection of channel catfish but the only substance which significantly reduced the parasite burden and improved the survival of I. necator-infected channel catfish was copper sulphate applied at a rate of $2.1 \mathrm{mg} \cdot \mathrm{L}^{-1}$ (once daily at $24-\mathrm{h}$ intervals for 3 days).

\footnotetext{
* Correspondence: Professor Kurt Buchmann, University of Copenhagen, Faculty of Health and Medical Sciences, Department of Veterinary Disease Biology,
} Stigbøjlen 7, DK-1870 Frederiksberg C., Denmark, phone: +45-35332700, e-mail: kub@sund.ku.dk. 
Formaldehyde has been widely applied as a general treatment of ectoparasites infecting various fish species (FajerAvila et al. 2003). In addition, trout farmers in many countries are currently using formaldehyde for control of ichthyobodosis but although bath treatment of salmonids against $I$. necator infection by formaldehyde has been found effective the compound may be banned due to its carcinogenicity, allergenicity, and adverse environmental impact. Therefore there is a need for alternative methods/chemicals for elimination of these parasites. We have performed a comparative study including several environmentally-friendly chemicals such as sodium percarbonate, peracetic acid, hydrogen peroxide, and formaldehyde to determine their effects on I. necator. One or more of these substances have previously been suggested as potential candidates in fish farms for control of various parasitic diseases (Rach et al. 2000), white spot disease caused by Ichthyophthirius multifiliis (see Buchmann and Kristensson 2003, Buchmann et al. 2003, Heinecke and Buchmann 2009, Bruzio and Buchmann, 2010), fungal infections (Straus et al. 2012), eye flukes (Larsen et al. 2005), and ichthyobodosis (Farmer et al. 2013). The presently reported study yielded new comparative data.

\section{MATERIALS AND METHODS}

Fish. Rainbow trout fry (body weight 2-3 g), (Fousing trout farm strain, Jutland, Denmark) were hatched from disinfected eggs and subsequently reared at a pathogenfree rearing facility at the Bornholm Salmon Hatchery, Nexø, Denmark. Prior to experimentation fish were transferred to the experimental facilities at the University of Copenhagen, and acclimated for three weeks. Water was recirculated in 200-L tanks equipped with internal filters (Eheim $\mathrm{GmbH} \& \mathrm{Co} \mathrm{KG}$, Deizisau, Germany) at $13^{\circ} \mathrm{C}$ under a constant $12: 12 \mathrm{~h}$ light-dark cycle. Fish were fed standard dry pelleted feed (Biomar A/S, Brande, Denmark) at the rate of $1 \%$ of their biomass per day. Water used was municipal water mixed with demineralized water $(1: 1)$ and every day $50 \%$ of the water was replaced. Daily concentrations of nitrate, nitrite, calcium and magnesium hardness, carbonate hardness, ammonia, and $\mathrm{pH}$ were measured on a regular basis (Tetra 6 in 1, Eldorado, Denmark) $\left(\mathrm{NO}^{3-}<10 \mathrm{mg} \cdot \mathrm{L}^{-1}, \mathrm{NO}^{2-}<0.1 \mathrm{mg} \cdot \mathrm{L}^{-1}\right.$,
Calcium and Magnesium $143 \mathrm{mg} \cdot \mathrm{L}^{-1}$, carbonate hardness $\mathrm{KH} 108 \mathrm{mg} \cdot \mathrm{L}^{-1}, \mathrm{NH}_{3}$ (not detectable), $\mathrm{pH}$ 7.2). Oxygen content was kept at $100 \%$ by continuous aeration. No mortality was observed during the rearing period.

Parasite culture. A laboratory culture of Ichthyobodo necator was originally obtained from heavily infected fish from a traditional trout farm (Graulund, Jutland, Denmark). The parasite population was maintained through serial passage to naive rainbow trout in laboratory fish tanks.

Experimental infection. Rainbow trout fry were experimentally infected with $I$. necator by cohabitation (10-14 days) in a 100-L tank containing fish (same body size) (one infected fish to three uninfected fish). Infected fish (donor fish) were tagged by fin-clipping in order to distinguish them from uninfected fish (recipient fish).

Test compounds and treatment. Before treatments trials were initiated a preliminary study was performed to test if the fish tolerated sodium percarbonate (SPC), peracetic acid (PAA), hydrogen peroxide (HP), and formaldehyde (FA). Fish were exposed to a dilution series of the compounds and observed for $2 \mathrm{~h}$ while their behaviour was recorded. Fish exposed to SPC $\left(40 \mathrm{mg} \cdot \mathrm{L}^{-1}, 80 \mathrm{mg} \cdot \mathrm{L}^{-1}\right.$, and $\left.120 \mathrm{mg} \cdot \mathrm{L}^{-1}\right)$, FA $\left(40 \mathrm{mg} \cdot \mathrm{L}^{-1}\right.$ and $\left.80 \mathrm{mg} \cdot \mathrm{L}^{-1}\right)$, and PAA $\left(0.1 \mathrm{mg} \cdot \mathrm{L}^{-1}, 0.2 \mathrm{mg} \cdot \mathrm{L}^{-1}\right.$, and $\left.0.3 \mathrm{mg} \cdot \mathrm{L}^{-1}\right)$ exhibited normal behaviour. The compounds were then tested for effects on parasites: sodium percarbonate SP (40, 80, and $120 \mathrm{mg} \cdot \mathrm{L}^{-1}$ ) (as previously used by Buchmann and Kristensson 2003, Buchmann et al. 2003), peracetic acid PAA $\left(0.1,0.2\right.$, and $0.3 \mathrm{mg} \cdot \mathrm{L}^{-1}$ ) (as tested by Bruzio and Buchmann 2010), hydrogen peroxide $\mathrm{HP}\left(15\right.$ and $\left.30 \mathrm{mg} \cdot \mathrm{L}^{-1}\right)$ (according to Rach et al. 2000), and formaldehyde FA (40 and $80 \mathrm{mg} \cdot \mathrm{L}^{-1}$ ) (see Buchmann and Kristensson 2003) (Tables 1, 2, and 3). Chemical compounds (SPC, FA, PAA, and HP) were applied by adding chemicals directly into individual 20 -L tanks with aerated water $(10 \mathrm{~L}$ consisting of municipal and demineralized water $1: 1)$ at $13^{\circ} \mathrm{C}$. Tests were performed in duplicate with 5 fish in each tank. The water was completely replaced after $2 \mathrm{~h}$ exposure and the efficacy of different chemicals was checked. Control fish were handled similarly but only exposed to pure water. Due to the time needed for counting parasites three trials on three consecutive days were performed. This secured that all fish were examined with-

Effects of sodium percarbonate (SPC) and formaldehyde (FA) at two different concentrations on Ichthyobodo necator populations on rainbow trout, Oncorhynchus mykiss

\begin{tabular}{lccc}
\hline Treatment & No. of fish & No. of parasites & $\begin{array}{c}\text { Statistics Student's } \\
t \text {-test }\end{array}$ \\
\hline Control & 10 & $36.3 \pm 7.8$ & $P<0.001$ \\
SPC $40 \mathrm{mg} \cdot \mathrm{L}^{-1}$ & 10 & $21.1 \pm 4.8$ & $P<0.001$ \\
$\mathrm{SPC} 80 \mathrm{mg} \cdot \mathrm{L}^{-1}$ & 10 & $15.2 \pm 15.6$ & $P<0.001$ \\
FA $40 \mathrm{mg} \cdot \mathrm{L}^{-1}$ & 10 & $8.6 \pm 7.4$ & $P<0.001$ \\
FA $80 \mathrm{mg} \cdot \mathrm{L}^{-1}$ & 10 & $1.2 \pm 2.5$ & \\
\hline
\end{tabular}

Values of parasite numbers are mean \pm standard deviation (mean number per microscope view field: $3 \times 0.785 \mathrm{~mm}^{2}$ ); Duplicate groups of five were combined as no significant differences between groups were found. 
in $2 \mathrm{~h}$ after treatment although the initial parasite density differed from day to day. Therefore untreated control groups were included each day.

Counting of parasites. After 2-h exposure the infection intensity was determined. Fish were euthanized by brain incision using a scalpel and parasites were then isolated by scraping the fish body surface (left and right side), gills, and fins onto a microscope slide. The sample was mixed with 3 drops of water, cover-slipped, and examined under a compound microscope (Olympus SZ30 at $\times 200$ magnification), whereby the numbers of parasites were counted on three randomly selected zones (visual field $0.785 \mathrm{~mm}^{2}$ ). The mean No. of flagellates per visual field in each group (corresponding to the mean of $5 \times 3=15$ counts) was calculated. Further an estimate of the total number of parasites recovered (all parasites under the cover slip $24 \mathrm{~mm} \times 36 \mathrm{~mm}$, area $864 \mathrm{~mm}^{2}$ ) was obtained. Data analysis. The data for duplicate groups were combined as no significant differences were detected between

Table 2

Effects of peracetic acid (PAA) and hydrogen peroxide (HP) at two different concentrations on Ichthyobodo necator populations on rainbow trout, Oncorhynchus mykiss

\begin{tabular}{lccl}
\hline Treatment & No. of fish & No. of parasites & $\begin{array}{c}\text { Statistics } \\
\text { Student's } \\
t \text {-test }\end{array}$ \\
\hline Control & 10 & $67.1 \pm 26.0$ & \\
PAA $0.1 \mathrm{mg} \cdot \mathrm{L}^{-1}$ & 10 & $37.6 \pm 17.3$ & $P<0.01$ \\
PAA $0.2 \mathrm{mg} \cdot \mathrm{L}^{-1}$ & 10 & $22.1 \pm 9.4$ & $P<0.001$ \\
HP $15 \mathrm{mg} \cdot \mathrm{L}^{-1}$ & 10 & $37.8 \pm 19.1$ & $P<0.01$ \\
HP $30 \mathrm{mg} \cdot \mathrm{L}^{-1}$ & 10 & $9.8 \pm 13.8$ & $P<0.001$ \\
\hline
\end{tabular}

Values of parasite numbers are mean \pm standard deviation (mean number per microscope view field: $3 \times 0.785 \mathrm{~mm}^{2}$ ) Duplicate groups of five were combined as no significant differences between groups were found. these groups as tested by Student's $t$-test. Normality test (Shapiro-Wilk) was used for evaluation of the normal distribution of data within each group. Student's $t$-test was used to detect differences between bath treated fish and control fish at each day. Efficacies for each compound at each concentration were expressed as percentage reduction of parasite numbers in treated compared to untreated control groups (Table 4).

Ethical issues. The presently reported study was conducted in accordance with the Danish regulations for experimental animal research.

\section{RESULTS}

The experimental infection resulted in parasite burdens up to more than 142000 flagellates per fish. Formaldehyde and peracetic acid were the most effective compounds showing an almost complete elimination (a reduction of 93-96 percentage points) of parasites at a concentrations of $80 \mathrm{mg} \cdot \mathrm{L}^{-1}(\mathrm{FA})$ and $0.3 \mathrm{mg} \cdot \mathrm{L}^{-1}(\mathrm{PAA})$ respectively,

Table 3

Effects of sodium percarbonate (SPC) and peracetic acid (PAA) at higher concentrations on Ichthyobodo necator population on rainbow trout, Oncorhynchus mykiss

\begin{tabular}{lccc}
\hline Treatment & No. of fish No. of parasites & $\begin{array}{c}\text { Statistics } \\
\text { Student's } \\
t \text {-test }\end{array}$ \\
\hline Control & 10 & $94 \pm 82$ & \\
SPC $120 \mathrm{mg} \cdot \mathrm{L}^{-1}$ & 10 & $15 \pm 29$ & $P<0.01$ \\
PAA $0.3 \mathrm{mg} \cdot \mathrm{L}^{-1}$ & 10 & $6 \pm 8$ & $P<0.01$ \\
\hline
\end{tabular}

Values of parasite numbers are mean \pm standard deviation (mean number per microscope view field: $3 \times 0.785 \mathrm{~mm}^{2}$ ); Duplicate groups of five were combined as no significant differences between groups were found.

Table 4

The reduction in Ichthyobodo necator parasite number per fish (Oncorhynchus mykiss) with respect to control group (infected) after water bath exposure using three auxiliary compounds

\begin{tabular}{lccc}
\hline Compound tested & $\begin{array}{c}\text { Concentration } \\
{\left[\mathrm{mg} \cdot \mathrm{L}^{-1}\right]}\end{array}$ & No. of fish & $\begin{array}{c}\text { Reduction of infection } \\
\text { [percentage points] }\end{array}$ \\
\hline Sodium percarbonate & 40 & 10 & 41.93 \\
& 80 & 10 & 57.51 \\
Formaldehyde & 120 & 10 & 83.63 \\
\hline & 40 & 10 & 76.12 \\
Peracetic acid & 80 & 10 & 96.77 \\
\hline Hydrogen peroxide & 0.1 & 10 & 42.27 \\
\hline
\end{tabular}

Reduction of infection $=$ reduction in parasite number per fish with respect to infected control. 
within $2 \mathrm{~h}$ of exposure (Tables 1, 3, and 4). Also other substances such as sodium percarbonate (SPC) and hydrogen peroxide (HP) significantly reduced the parasite burden (compared to control untreated fish) when applied at concentrations of $80 \mathrm{mg} \cdot \mathrm{L}^{-1}$ and $15 \mathrm{mg} \cdot \mathrm{L}^{-1}$, respectively (Tables 2 and 4). The only chemical which elicited adverse effects in the fish was hydrogen peroxide at a concentration of $30 \mathrm{mg} \cdot \mathrm{L}^{-1}$ (all HP exposed fish showed abnormal behaviour including balance disturbances after $2 \mathrm{~h}$ of exposure).

\section{DISCUSSION}

The presently reported experiments demonstrated that among the compounds tested the formaldehyde was the most effective for elimination of Ichthyobodo necator from skin and fins of young rainbow trout. It was, however, closely followed by peracetic acid while sodium percarbonate showed also some treatment efficacy. The low toxicity of both SPC and PAA suggests a potential of those compounds for increasing the concentration or the exposure time.

PAA was previously shown to kill Ichthyophthirius multifiliis theronts, the causative agent of white spot disease (Bruzio and Buchmann 2010) and to cure infected common carp (Cyprinus carpio L.) without eliciting any adverse effects in fish (Sudová et al. 2010). Likewise, SPC has proved effective in killing theronts of I. multifiliis (see Buchmann et al. 2003, Heinecke and Buchmann 2009) and Buchmann and Kristensson (2003) showed that SPC at a concentration of $80 \mathrm{mg} \cdot \mathrm{L}^{-1}$ after $18 \mathrm{~h}$ of exposure eradicated Gyrodactylus derjavinoides on rainbow trout which suggested that SPC may act as an alternative to formaldehyde for reducing parasitic populations on rainbow trout.

Exposure to HP $\left(30 \mathrm{mg} \cdot \mathrm{L}^{-1}\right)$ reduced the parasite load within $2 \mathrm{~h}$, but the chemical also induced adverse reactions in the fish. Usage of SPC (releasing HP) did not induce any toxic effects in the fish, which may be explained by the slow and gradual release of HP from SPC which would prevent a peak toxic concentration. Arndt and Wagner (1997) and Rach et al. (2000) suggested HP to be safe at various concentrations and dosages. However, a number of factors including temperature, fish age, size and species, exposure time, water quality (organic matter content and hardness), and other environmental conditions must be considered when evaluating efficacy and toxicity. Therefore it is recommended that preliminary tests should be made before a given species of fish are treated (Cross and Hursey 1973, Gaikowski et al. 1999).

In conclusion, SPC and PAA were shown to be effective auxiliary compounds for treatment of water with Ichthyobodo necator infected young rainbow trout when used in $2 \mathrm{~h}$ static baths at a concentration of $120 \mathrm{mg} \cdot \mathrm{L}^{-1}$ and $0.3 \mathrm{mg} \cdot \mathrm{L}^{-1}$, respectively. Although formaldehyde still proved to be effective for parasite elimination the toxicity of this chemical question its future use. Therefore, SPC and PAA substances may be applied as alternatives to formaldehyde for controlling ichthyobodosis in fish farms. In addition, it should be noted that effects of exposure time, dosage, water quality (including $\mathrm{pH}$, hardness and organic content), and other environmental factors including water temperature may affect efficacy and effect on fish which call for further detailed testing before any use in a specific aquaculture system.

\section{ACKNOWLEDGEMENTS}

The present work was supported by the Danish Ministry of Food, Agriculture and Fisheries and by the European Commission through a grant from the European Fisheries Fund (3744-11-k-0197).

\section{REFERENCES}

Arndt R.E., Wagner E.J. 1997. The toxicity of hydrogen peroxide to rainbow trout Oncorhynchus mykiss and cutthroat trout Oncorhynchus clarki fry and fingerlings. Journal of the World Aquaculture Society 28 (2): 150-157. DOI: 10. 1111/j.1749-7345.1997.tb00850.x

Bruzio M., Buchmann K. 2010. The effect of peracetic acid products on parasites causing white spot disease. Fish Farmer 6: 25-27.

Buchmann K., Jensen P.B., Kruse K.D. 2003. Effects of sodium percarbonate and garlic extract on Ichthyophthirius multifiliis theronts and tomocysts: in vitro experiments. North American Journal of Aquaculture 65 (1): 21-24. DOI: 10.1577/1548-8454(2003)065<0021:EOSPAG $>2.0 . C O ; 2$

Buchmann K., Kristensson R. T. 2003. Efficacy of sodium percarbonate and formaldehyde bath treatments against Gyrodactylus derjavini infestations of rainbow trout. North American Journal of Aquaculture 65 (1): 25-27. DOI: 10.1577/1548-8454(2003)065<0025:EOSPAF $>2.0$. CO;2

Cross D.G., Hursey P.A. 1973. Chloramine-T for the control of Ichthyophthirius multifiliis (Fouquet). Journal of Fish Biology 5 (6): 789-798. DOI: 10.1111/j.1095-8649. 1973.tb04512.x

Fajer-Ávila E.J., Abdo-de la Parra I. A., Aguilar-Zarate G., Contreras-Arce R., Zaldívar-Ramírez J., BetancourtLozano M. 2003. Toxicity of formalin to bullseye puffer fish (Sphoeroides annulatus Jenyns, 1843) and its effectiveness to control ectoparasites. Aquaculture 223 (1-4): 41-50. DOI : $10.1016 /$ S0044-8486(03)00166-2

Farmer B.D., Straus D.L., Beck B.H., Mitchell A.J., Freeman D., Meinelt T. 2013. Effectiveness of copper sulphate, potassium permanganate and peracetic acid to reduce mortality and infestation of Ichthyobodo necator in channel catfish Ictalurus punctatus (Rafinesque 1818). Aquaculture Research 44 (7): 1103-1109. DOI: 10.1111/j.13652109.2012.03118.x

Gaikowski M.P., Rach J.J., Ramsay R.T. 1999. Acute toxicity of hydrogen peroxide treatments to selected life stages of cold-, cool-, and warmwater fish. Journal of Aquaculture 178 (3-4): 191-207. DOI: 10.1016/S0044-8486(99)00123-4

Heinecke R.D., Buchmann K. 2009. Control of Ichthyophthirius multifiliis using a combination of water filtration and sodium percarbonate: Dose-response studies. Journal of Aquaculture 288 (1-2): 32-35. DOI: 10. 1016/j.aquaculture.2008.11.017

Larsen A.H., Bresciani J., Buchmann K. 2005. Pathogenicity of Diplostomum cercaria in rainbow trout, and alternative 
measures to prevent diplostomosis in fish farms. European Association of Fish Pathologists 25 (1): 20-26.

Rach J.J., Gaikowski M.P., Ramsay R.T. 2000. Efficacy of hydrogen peroxide to control parasitic infestations on hatchery-reared fish. Journal of Aquatic Animal Health 12 (4): 267-273. DOI: $10.1577 / 1548-8667(2000) 012<0267$ :EOHPTC $>2.0 . \mathrm{CO} ; 2$

Straus D. L., Meinelt T., Farmer B. D., Mitchell A. J. 2012. Peracetic acid is effective for controlling fungus on channel catfish eggs. Journal of Fish Diseases 35 (7): 505-511. DOI: $10.1111 / \mathrm{j} .1365-2761.2012 .01383 . x$

Sudová E., Straus D.L., Wienke A., Meinelt T. 2010. Evaluation of continuous 4-day exposure to peracetic acid as a treatment for Ichthyophthirius multifiliis. Parasitology Research 106 (2): 539-542. DOI: 10.1007/s00436-0091666-8

Tojo J. L., Santamarina M.T. 1998. Oral pharmacological treatments for parasitic diseases of rainbow trout Oncorhynchus mykiss. III: Ichthyobodo necator. Journal of Diseases of Aquatic Organisms 33 (3): 195-199. DOI: 10.3354/dao033195

Tojo J.L., Santamarina M.T., Leiro J., Ubeira F.M., Sanmartin M.L. 1994. Pharmacological treatments against Ichthyobodo necator (Henneguy, 1883) in rainbow trout,
Oncorhynchus mykiss (Walbaum). Journal of Fish Diseases 17 (2): 135-134. DOI: 10.1111/j.1365-2761.1994.tb00206.x

Urawa S. 1992. Host range and geographical distribution of the ectoparasitic protozoans Ichthyobodo necator, Trichodina truttae and Chilodonella piscicola on hatchery-reared salmonids. Scientific Reports of the Hokkaido Salmon Hatchery 46: 175-203.

Urawa S. 1993. Effects of Ichthyobodo necator infections on seawater survival of juvenile chum salmon (Oncorhynchus keta). Aquaculture 110 (2): 101-110. DOI: 10.1016/00448486(93)90264-Y

Urawa S., Kusakari M. 1990. The survivability of the ectoparasitic flagellate Ichthyobodo necator on chum salmon fry (Oncorhynchus keta) in seawater and comparison to Ichthyobodo sp. on Japanese flounder (Paralichthys olivaceus). Journal of Parasitology 76 (1): 33-40. DOI: $10.2307 / 3282624$

Received: 20 December 2012 Accepted: 27 May 2013 Published electronically: 30 June 2013 